\title{
Fatores influenciadores do desempenho em programas de transplante de órgãos no Brasil: estudo de caso com coordenadores estaduais de transplante
}

\section{Marina Martins Siqueira Claudia Affonso Araujo}

\section{INTRODUÇÃO} dedicados à gestão da área: os coordenadores de transplante (ELIZALDE e LORENTE, 2006). Inspirado no sistema espanhol, cada estado brasileiro possui um coordenador atuando em sua respectiva central estadual de transplante. O coordenador deve atuar de maneira harmoniosa com os objetivos, regras e instituições do Sistema Nacional de Transplantes. Isto inclui a coordenação dos hospitais captadores e transplantadores, as equipes de doação e transplante e todos os elementos que englobam as atividades da área em nível estadual, servindo como canal de comunicação, suporte e ponto de referência para atingir metas e padrões de qualidade estaduais e nacionais (ELIZALDE e LORENTE, 2006). A doação e transplante de órgãos representa um fenômeno social intricado, com alto grau de participação humana, relevância social e complexidade técnico-gerencial (KHETPAL e MOSSIALOS, 2018). Contudo, são escassos os estudos voltados ao entendimento em profundidade de problemas e práticas (T)enciais na perspectiva de atores relevantes (TONG, MORTON e WEBSTER, 2016). A despeito do proeminente papel dos coordenadores nos resultados da área, a perspectiva desses profissionais é pouco explorada do ponto de vista gerencial.

\section{OBJETIVO}

presente estudo tem como objetivo investigar fatores influenciadores do desempenho em programas estaduais de ransplante de órgãos no Brasil. O exame se dá sob a perspectiva dos coordenadores estaduais de transplante, responsáveis pela gestão dos programas de transplante em seus respectivos estados. Para tal, a seguinte pergunta de ONER et al., 2016; TAYLOR et al., 2015; MOSADEGHRAD, 2014; LIU e ITOH, 2013): efunções de trabalho dos coordenadores e (4) aos pacientes e usuários dos serviços afetam os resultados obtidos pelos programas estaduais de transplante?"

Não foi identificado até então trabalho semelhante aplicado ao contexto brasileiro. Assim, pretende-se proporcionar um panorama inicial sobre a coordenação de programas de transplantes no Brasil, contribuindo também para
literatura de pesquisas qualitativas e de cunho gerencial em serviços de doação e transplante.

\begin{tabular}{|c|c|c|c|}
\hline & \multicolumn{3}{|c|}{ Tabela 1. Perfil dos entrevistados } \\
\hline \multirow{4}{*}{ Trata-se de um estudo de caso qualitativo, com } & Formação & $\begin{array}{c}\text { Tempo } \\
\text { no cargo }\end{array}$ & $\begin{array}{l}\text { Dedicação } \\
\text { exclusiva }\end{array}$ \\
\hline & Enfermeiro(a) & 8 anos & $\operatorname{sim}$ \\
\hline & Médico(a) - hepatologista & 3 anos & Não \\
\hline & Médico(a) - hematologista & 3 anos & Sim \\
\hline \multirow{3}{*}{$\begin{array}{l}\text { entrevistas semiestruturadas de questões } \\
\text { abertas com coordenadores de quinze estados }\end{array}$} & Assistente social & 15 anos & Sim \\
\hline & Enfermeiro(a) & 18 anos & Não \\
\hline & Psicólogo(a) - clínica & 4 anos & Sim \\
\hline \multirow{3}{*}{$\begin{array}{l}\text { brasileiros. A abordagem permitiu investigar a } \\
\text { perguntas de "como" e "porque" ainda que }\end{array}$} & Enfermeiro(a) & 8 anos & Sim \\
\hline & Enfermeiro(a) & 7 anos & Sim \\
\hline & Farmacêutico(a) & 2 anos & Sim \\
\hline \multirow{3}{*}{$\begin{array}{l}\text { hajam escassos estudos anteriores no tópico } \\
\text { (YIN, 2014). As entrevistas foram realizadas via }\end{array}$} & Médico(a) - nefrologista & 3 anos & Sim \\
\hline & Médico(a) - intensivista & 15 anos & Não \\
\hline & Médico(a) - nefrologista & 1 ano & Sim \\
\hline \multirow[t]{3}{*}{ Skype ou presencialmente. } & Enfermeiro(a) & 6 anos & Sim \\
\hline & Médico(a) - intensivista & 7 anos & Não \\
\hline & Médico(a) - sanitarista & 13 anos & Sim \\
\hline
\end{tabular}

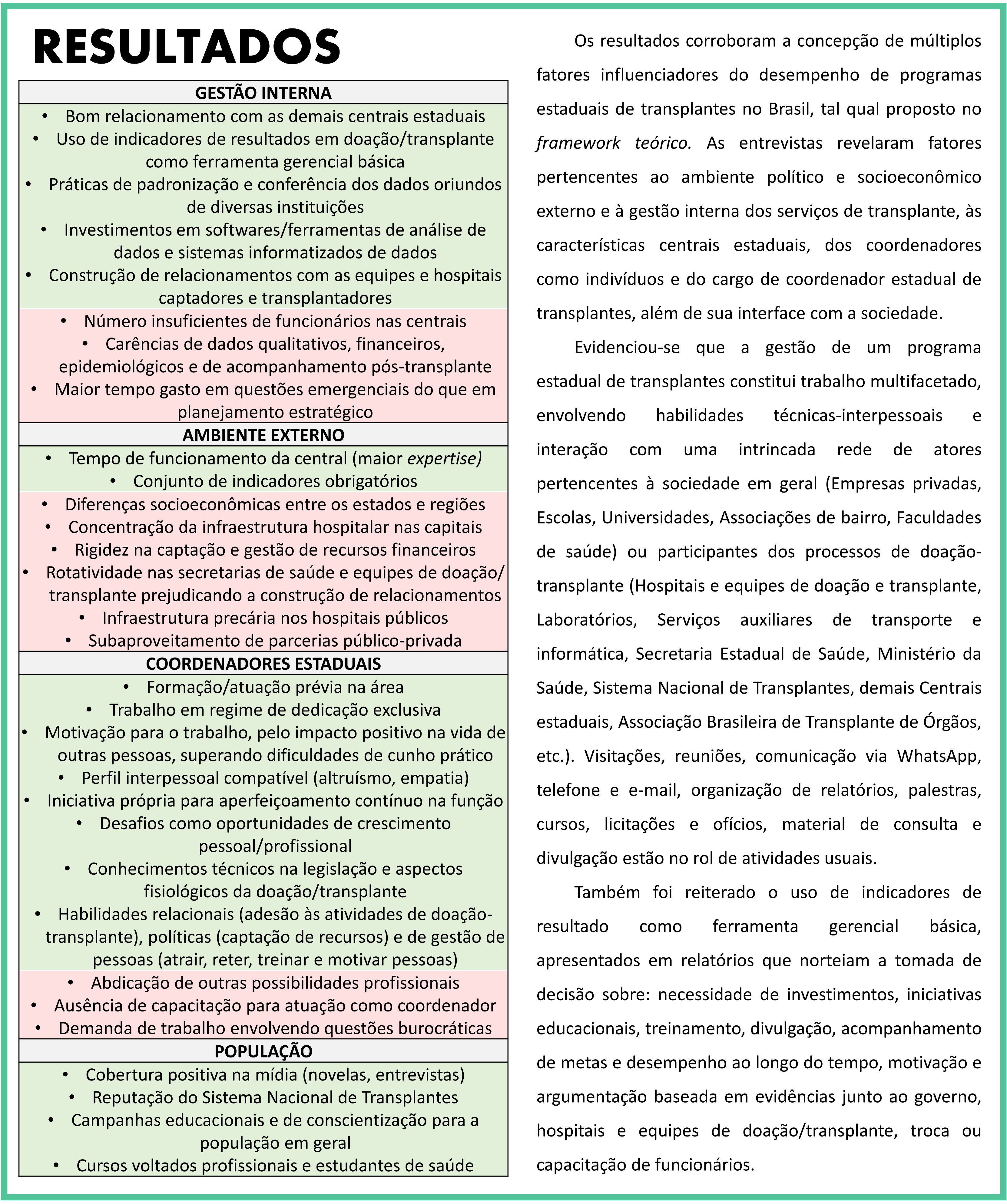

\section{REFERÊNCIAS}

Oner, N.; Zengul, F. D.; Ozaydin, Associated with Hospital Financial Performance: A Systematic Review. Journal of Health Care Finance. 2016

Taylor N, Clay-Williams R, Hogden E, Braithwaite J, Groene O. High performing hospitals: a qualitative syste Mosadeghrad, A. M. Factors influencing healthcare service quality. Int J Health Policy and Manag, 2014, 3(2), 77-89 Liu, H.; Itoh, K. Conceptual Framework for Holistic Dialysis Management Based on Key Performance Indicators.
Therapeutic Apheresis and Dialysis 2013; 17(5):532-550.

Khetpal, V. Mossialos. E. An ethical appraisal of living-anonymous kidney donation using Adam Smith's Theory of Moral Sentiments. Health Policy, 2018, 122(11): 1212-1221.

Tong, A.; Morton, R. L.; Webster A. C. How Qualitative Research Informs Clinical and Policy Decision Making in Transplantation: A Review. Transplantation, 2016, 100(9): 1997-2005,

M. Coordination and DOnation. An Sist

Yin, R. K. Case Study Research Design and Methods. 5th ed., Thousand Oaks, CA: Sage, 282 p. 